\title{
Obesity-induced insulin resistance via changes in the DNA methylation profile of insulin pathway genes
}

\author{
Małgorzata Małodobra-Mazur ${ }^{1, A, C-F}$, Aneta Alama ${ }^{1, B, C}$, Dorota Bednarska-Chabowska ${ }^{2, B}$, \\ Dorota Pawelka ${ }^{3, B}$, Aneta Myszczyszyn ${ }^{4, B}$, Tadeusz Dobosz ${ }^{1, A}$ \\ ${ }^{1}$ Molecular Techniques Unit, Department of Forensic Medicine, Wroclaw Medical University, Poland \\ ${ }^{2}$ Department of Angiology, Hypertension and Diabetology, Wroclaw Medical University, Poland \\ ${ }^{3} 1^{\text {st }}$ Department and Clinic of General, Gastroenterological and Endocrinological Surgery, Wroclaw Medical University, Poland

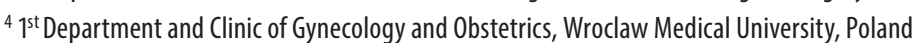 \\ A - research concept and design; $\mathrm{B}$ - collection and/or assembly of data; $\mathrm{C}$ - data analysis and interpretation; \\ $D$ - writing the article; $E$ - critical revision of the article; $F$ - final approval of the article
}

\section{Address for correspondence}

Małgorzata Małodobra-Mazur

E-mail:malgorzata.malodobra-mazur@umed.wroc.pl

\section{Funding sources}

Statutory activity - maintain the research capacity,

Wroclaw Medical University, ST.A122.16.030

Conflict of interest

None declared

Received on April 23, 2019

Reviewed on May 7, 2019

Accepted on June 27, 2019

Published online on November 25, 2019

\section{Cite as}

Małodobra-Mazur M, Alama A, Bednarska-Chabowska D, Pawelka D, Myszczyszyn A, Dobosz T. Obesity-induced insulin resistance via changes in the DNA methylation profile of insulin pathway genes. Adv Clin Exp Med. 2019;28(12):1599-1607. doi:10.17219/acem/110321

DOI

10.17219/acem/110321

\section{Copyright}

Copyright by Author(s)

This is an article distributed under the terms of the

Creative Commons Attribution 3.0 Unported (CC BY 3.0)

(https://creativecommons.org/licenses/by/3.0/)

\section{Abstract}

Background. Obesity has been shown to play a key role in the development of insulin resistance (IR). Abundant data implicate obesity in DNA hypermethylation at global and site-specific levels, including genes regulating insulin sensitivity. Deregulation of epigenetic marks implicates gene expression and changes in cell metabolism.

Objectives. Our previous reports demonstrated that the strongest risk factor in the development of IR is BMl; accordingly, the objective of this study was to investigate the effect of obesity on DNA methylation and insulin sensitivity.

Material and methods. A study was carried out on lymphocytes (N-34) and visceral adipose tissue (VAT; $\mathrm{N}-35$ ) of insulin-resistant subjects and healthy controls. Genetic material (DNA and RNA) was extracted from cells. Global and site-specific DNA methylation was analyzed with the use of restriction enzymes followed by real-time polymerase chain reaction (PCR). Gene expression was analyzed as relative mRNA level normalized to a housekeeping gene.

Results. Global DNA methylation increased in both types of tissue in obese and insulin-resistant individuals and correlated positively with IR. Two of the 3 investigated promoters of insulin pathway genes were hypermethylated, which correlated negatively with gene expression and positively with IR. The DNMT3a gene was upregulated in obese insulin-resistant individuals in both types of tissues and correlated positively with global DNA methylation.

Conclusions. DNA methylation profile changed depending on body mass index (BMI) and influenced glucose metabolism and insulin sensitivity in VAT.

Key words: obesity, insulin resistance, DNA methylation, insulin signaling pathway 


\section{Introduction}

Overweight and obesity are among the leading problems of modern civilization. Obesity plays a key role in the development of insulin resistance (IR), leading to other metabolic disorders along with the consequent development of type 2 diabetes (T2D). ${ }^{1}$ Insulin resistance is defined as a state in which a standard amount of insulin is insufficient to develop the physiological response of the cell, i.e., increasing glucose uptake, storage and oxidation. ${ }^{2}$

Population and family studies confirmed the genetic background of both obesity and IR, suggesting susceptible loci as one of the causes of both conditions. However, the impact of the genetic background on the induction of obesity and obesity-related disorders turned out to be relatively modest. In both conditions (obesity and IR), the key role is played by gene-environment interaction; accordingly, epigenetic changes in chromatin structures and gene function may be responsible for genetic susceptibility. ${ }^{3}$ Epigenetic markers are believed to explain the link between gene-lifestyle interactions and the pathogenesis of numerous metabolic disorders and have even been proposed as specific biomarkers of metabolic disorders and possible therapeutic targets. ${ }^{4}$

Epigenetic modification is defined as the heritable and reversible modification of gene expression without changes in the DNA sequence, maintained over generations. ${ }^{5}$ Epigenetic modifications include DNA methylation, the positioning of nucleosomes, and modifications in histones. All of these modifications are involved in establishing and maintaining the 2 major forms of chromosomal structure: the inactive heterochromatin and the transcriptionally active euchromatin. ${ }^{6-10}$

Indeed, abundant data implicate obesity in DNA hypermethylation at both global and site-specific levels, including genes regulating insulin sensitivity, such as $A D I P O Q$, $L P L$, or PPAR ${ }^{11-13}$ Zheng et al. reported a link between obesity and methylation of mtDNA (mitochondrial DNA). ${ }^{14}$ Analysis of DNA methylation carried out before and after weight loss revealed a differentially methylated region of the genome correlated with numerous genes, including 21 genes regulating insulin sensitivity. ${ }^{15}$ A genome-wide DNA methylation study showed the differentially methylated profiles of numerous $\mathrm{CpG}$ sites in visceral adipose tissue (VAT) of insulin-resistant vs insulin-sensitive obese individuals. ${ }^{16}$ On the other hand, caloric restriction was demonstrated to modulate chromatin function and increase genome stability mainly by reversing DNA methylation, which correlated with improving insulin sensitivity and whole-body weight reduction. ${ }^{17,18}$

The exact mechanism by means of which obesity influences insulin sensitivity via DNA methylation remains unclear. Some reports indicate the role of inflammatory cytokines. ${ }^{19}$ Our report, along with others, demonstrated that the greatest risk factor in the development of IR is body mass index (BMI). ${ }^{20,21}$ Accordingly, the effect of obesity on DNA methylation and its influence on insulin sensitivity was investigated in the present study.

\section{Material and methods}

The research protocols were approved by the ethical review board of Wroclaw Medical University, Poland (approval No. KB-556/2008).

\section{Population characterization}

All participants were informed about the purposes of the study and all subjects gave written consent for their participation in the study. The T2D patients were selected based on a diagnosis of T2D. Additionally, fasting glucose and insulin level, BMI, IR ratios (homeostatic model assessment of insulin resistance (HOMA-IR) or quantitative insulin sensitivity check index (QUICKI)), and lipid metabolism were assessed. Type 2 diabetic patients being treated with insulin were excluded. Lymphocytes (L) were collected from whole blood obtained from 13 types 2 diabetic patients ( 8 men and 5 women). The type 2 diabetic patients were inpatients of the Department of Angiology, Hypertension, and Diabetology, Wroclaw Medical University. Control lymphocytes were obtained from healthy subjects (11 men and 10 women) of similar age based on a fasting glucose level below $100 \mathrm{mg} / \mathrm{dL}$, the absence of diabetes in family history, and, for women, no history of gestational diabetes.

Visceral adipose tissue biopsies were collected during abdominal surgeries from 9 patients with T2D (3 men and 6 women) and from 26 controls ( 17 men and 9 women) of similar age. Adipose tissue donors were inpatients of the First Department and Clinic of General, Gastroenterological, and Endocrinological Surgery, Wroclaw Medical University, and of the $1^{\text {st }}$ Department and Clinic of Gynaecology and Obstetrics, Wroclaw Medical University. Controls were selected from patients without T2D undergoing abdominal surgery, based on a fasting glucose level below $100 \mathrm{mg} / \mathrm{dL}$, the absence of diabetes in family history, and, for women, no history of gestational diabetes. The aims of abdominal surgeries were mainly cholecystectomy, surgical repair of an abdominal hernia, or gastric surgery.

Additional excluding criteria for all subjects were as follows: other systemic diseases such as sclerosis, thyroid dysfunction, hepatitis, chronic inflammatory or infective diseases, neurological diseases, and tumors. Heavy drinkers or those with a positive history were also excluded.

\section{Body mass index and insulin resistance ratios}

Body mass index was calculated as the patient's weight in kilograms divided by the square of their height in meters $\left[\mathrm{kg} / \mathrm{m}^{2}\right]$. Overweight was defined as BMI $>25 \mathrm{~kg} / \mathrm{m}^{2}$, 
obesity as BMI $>30 \mathrm{~kg} / \mathrm{m}^{2}$. Insulin resistance rate was assessed using IR ratios calculated as follows ${ }^{22}$ :

1) HOMA-IR $[($ glucose $[\mathrm{mmol} / \mathrm{L}]$ * insulin $[\mu \mathrm{U} / \mathrm{mL}]) / 22.5]$,

2) QUICKI $[1 /(\log$ glucose $[\mathrm{mg} / \mathrm{dL}]+\log$ insulin $[\mu \mathrm{U} / \mathrm{mL}])]$. Insulin resistance was diagnosed on the basis of HOMAIR $>2.5$ and QUICKI $<0.321$.

\section{Lymphocyte preparation and visceral adipose tissue biopsy collection}

Lymphocytes were isolated from whole blood collected on anticoagulant using centrifugation on Grandison L (AquaLab, Warszawa, Poland). Five milliliters of the whole blood was placed on $2 \mathrm{~mL}$ of Grandison $\mathrm{L}$ and centrifuged at 2,000 rpm for $20 \mathrm{~min}$ at $4^{\circ} \mathrm{C}$. The lymphocytes ring was collected and washed twice with phosphate-buffered saline (PBS); the red blood cells were removed using a lysis buffer $\left(\mathrm{HH}_{4} \mathrm{Cl}, \mathrm{KHCO}_{3}\right.$, EDTA-Na $)$. Lymphocytes were suspended in PBS and centrifuged at maximum speed for 2 min at $4^{\circ} \mathrm{C}$; PBS was discarded and the pellet was frozen at $-80^{\circ} \mathrm{C}$ pending analysis.

Visceral adipose tissue biopsies taken from patients undergoing abdominal surgery were immediately placed in RNALater (Ambion), incubated at $4^{\circ} \mathrm{C}$ for $24 \mathrm{~h}$. The RNALater was discarded and the adipose tissue biopsies froze at $-80^{\circ} \mathrm{C}$ pending analysis.

\section{RNA extraction and gene expression study}

RNA was isolated from peripheral lymphocytes using a mirVana miRNA Isolation Kit (Ambion, Carlsbad, USA) according to the manufacturers' protocol for total RNA. RNA from VAT biopsies was isolated using TriPure Isolation Reagent (Roche, Basel, Switzerland) according to the manufacturers' protocol. The tissues were homogenized using $2.0 \mathrm{~mm}$ zirconia beads (BioSpec Products, Inc., Bartlesville, USA). Following homogenization, the tissues were centrifuged at maximum speed for 2 min at $4^{\circ} \mathrm{C}$ in order to collect the fatty deposit at the top of the tube, which was then discarded. The homogenate was extracted with $200 \mu \mathrm{L}$ of chloroform and centrifuged for $15 \mathrm{~min}$ at maximum speed at $4^{\circ} \mathrm{C}$. The aqueous phase was collected and the RNA precipitated with $500 \mu \mathrm{L}$ of isopropanol, centrifuged for $10 \mathrm{~min}$ at maximum speed, and washed with $1 \mathrm{~mL}$ of $70 \%$ ethanol. The RNA pellet was dissolved in RNase-Free Water and stored at $-80^{\circ} \mathrm{C}$.

Reverse transcription was performed with the use of a High-Capacity cDNA Reverse Transcription Kit (Applied Biosystems, Foster City, USA). INSR, PIK3R1, and $S L C 2 A 4$ gene expression levels were analyzed with realtime polymerase chain reaction (RT-PCR) with the use of TaqMan Gene Expression Assays (Applied Biosystems) and Real-Time PCR Universal Master Mix (Applied Biosystems). The following TaqMan Gene Expression Assays were used: INSR, Hs00961557_m1; PIK3R1, Hs00381459_m1; SLC2A4, Hs00168966_m1; $\beta$-actin, Hs00181698_m1.

The DNA methyltransferase (DNMT1, DNMT3a, and DNMT3b) expression rate was assessed via Real-Time PCR using a SensiFast SYBR Hi-ROX Kit (Bioline, London, UK). Primers were designed manually to span the exon-exon junction; specificity was checked using Primer-BLAST (NCBI); the secondary structures were analyzed using OligoAnalyzer 3.1 (IDT, Coralville, USA). Prior to RealTime PCR, the efficiency of primers was analyzed using the standard curve method; specificity was checked based on the denaturation curve. The primer sequences used for measurements of DNMT expression are presented in Table 1.

Table 1. Primers sequences used for gene expression analysis (DNMTs) and promoters methylation analysis (insulin pathway genes)

\begin{tabular}{|c|c|c|c|c|c|}
\hline Gene & Primer & Sequence $\left(5^{\prime} \rightarrow 3^{\prime}\right)$ & Size $\left(b p^{1}\right)$ & Location in gene & $\mathrm{R}^{2}$ \\
\hline \multirow{2}{*}{ DNMT1 } & forward & AGGCGGCTCAAAGATTTG & \multirow{2}{*}{57} & \multirow{2}{*}{$1-2$ exon } & \multirow{2}{*}{$97.5 \%$} \\
\hline & reverse & СТССТТСАСАСАТТССТТ & & & \\
\hline \multirow{2}{*}{ DNMT3a } & forward & CAGGATAGCCAAGTTCAGC & \multirow{2}{*}{120} & \multirow{2}{*}{ 17-18 exon } & \multirow{2}{*}{$97.0 \%$} \\
\hline & reverse & GTGCACCATAAGATGTCCTC & & & \\
\hline \multirow{2}{*}{ DNMT3b } & forward & ATGCTCTGGAGAAAGCTAG & \multirow{2}{*}{94} & \multirow{2}{*}{ 8-9 exon } & \multirow{2}{*}{$95.8 \%$} \\
\hline & reverse & CACTCCAACATGGGCTTCA & & & \\
\hline \multirow{2}{*}{$\beta$-actin } & forward & GAGAAGATGACCCAGATCA & \multirow{2}{*}{72} & \multirow{2}{*}{$2-3$ exon } & \multirow{2}{*}{$99.9 \%$} \\
\hline & reverse & TAGCACAGCCTGGATAGCAA & & & \\
\hline \multirow{2}{*}{ PIK3R1 } & forward & AGACACTCGGATTAGAGACG & \multirow{2}{*}{135} & \multirow{2}{*}{$\begin{array}{c}\text { 295-299 } \\
\text { upstream TSS } 2\end{array}$} & \multirow{2}{*}{$97.6 \%$} \\
\hline & reverse & AGTGCTCTGGCTCTACACG & & & \\
\hline \multirow{2}{*}{ INSR } & forward & GGTAGAGAAAGGATCTGTG & \multirow{2}{*}{73} & \multirow{2}{*}{$\begin{array}{c}\text { 628-632 } \\
\text { upstream TSS }\end{array}$} & \multirow{2}{*}{$99.2 \%$} \\
\hline & reverse & GAGTCTCCTCCAGTTTCAG & & & \\
\hline \multirow{2}{*}{ SLC2A4 } & forward & TGAAAGACAGGACCAAGCAG & \multirow{2}{*}{57} & \multirow{2}{*}{$\begin{array}{c}\text { 646-650 } \\
\text { upstream TSS }\end{array}$} & \multirow{2}{*}{$97.4 \%$} \\
\hline & reverse & CAGGAAATTCCGTTCCCAC & & & \\
\hline
\end{tabular}

${ }^{1}$ base pairs; ${ }^{2}$ transcription start site; ${ }^{3}$ efficiency assessed based on standard curve method. 


\section{DNA extraction and global and site-specific DNA methylation}

The VAT was dissected and digested with Collagenase A (Roche) overnight at $37^{\circ} \mathrm{C}$. DNA was then extracted with the use of a High Pure PCR Template Preparation Kit (Roche). DNA from lymphocytes was extracted using the same kit. The DNA concentration was assessed using NanoDrop ND1000 (Thermo Fisher Scientific, Waltham, USA).

Global DNA methylation in VAT and lymphocytes was measured using an EpiJET DNA Methylation Analysis Kit (Thermo Fisher Scientific) according to the manufacturers' protocol. Briefly, genomic DNA (500 ng from VAT and $200 \mathrm{ng}$ from lymphocytes) was digested with 2 restriction enzymes: HpaII and MspI. Both enzymes recognized the same DNA sequence (5'-CCGG-3'); however, when the internal $C$ within the recognized sequence was methylated, cleavage with HpaII was blocked, although unaffected with MspI. After digestion, the DNA treated with HpaII, MspI, and non-digested DNA was separated using $1.2 \%$ agarose gel stained with ethidium bromide. The bands of DNA digested with HpaII and non-digested DNA were analyzed using ImageJ (National Institutes of Health, Bethesda, USA). Global methylation was calculated as a percentage of non-digested DNA. Site-specific DNA methylation was analyzed using an EpiJET DNA Methylation Analysis Kit (Thermo Scientific). Real-time PCR was run following the digestion of enzymes using a SensiFast SYBR Hi-ROX Kit (Bioline). Primers were designed manually to hybridize within promoters of investigated genes flanking the recognition sequence (5'-CCGG-3'). Designed primers were analyzed according to specificity (Primer-BLAST, NCBI) and secondary structure formation (OligoAnalyzer 3.1; IDT). A CpG islands prediction was done using MethPrimer with CG content $>60 \%$ and an Obs/Exp ratio $>0.6$. Ct values were used to calculate the promoter methylation rate using the formula

$$
\% \text { of } 5-\mathrm{mC}=100 /(1+\mathrm{E})^{\mathrm{Cq} 2-\mathrm{Cq} 1}
$$

[E - PCR efficiency; Cq1 - threshold cycle of undigested DNA; Cq2 - threshold cycle of HpaII-digested DNA]

The sequences of primers used for promoters methylation analysis are presented in Table 1.

\section{Cytokine levels measurements}

Two inflammatory cytokine levels were measured in the plasma of the investigated subjects using commercial enzyme-linked immunosorbent assay (ELISA) kits: the PeliKine human IL-6 ELISA and PeliKine human TNFalpha ELISA Kits (Sanquin, Amsterdam, the Netherlands).

\section{Statistical analyses}

Statistical analyses were performed with the use of STATISTICA (StatSoft, Inc., Tulsa, USA). Statistical significance was set at $\mathrm{p}<0.05$. Differences between the clinical features of tested groups were assessed using Student's t-test. Correlation between gene expression level and biochemical parameters was done using Pearson's coefficient of correlation. The power of the study was assessed using STATISTICA. The gene expression level was analyzed as relative gene expression normalized to $\beta$-actin using the $\Delta \Delta \mathrm{Ct}$ quantification model. ${ }^{23}$

\section{Results}

\section{Characterization of study groups}

The characterization of enrolled patients was carried out according to the type of biological material (patients from whom lymphocytes or adipose tissues samples were collected). Type 2 diabetic patients in both analyses were characterized by increased BMI and glucose and insulin levels, as well as by IR resistance ratios (HOMA-IR and QUICKI). Moreover, an increase in adiponectin and HDL levels were observed in control patients. However, when dividing enrolled patients according to BMI as lean $\left(<25 \mathrm{~kg} / \mathrm{m}^{2}\right)$ or obese $\left(\geq 25 \mathrm{~kg} / \mathrm{m}^{2}\right)$, in addition to the above changes, increased TG and IL- 6 levels were observed, while $\mathrm{HDL}$ and adiponectin levels were decreased in obese subjects. A detailed characterization of the study cohort is presented in Table 2.

\section{Global DNA methylation}

Global DNA methylation was measured in the L and VAT of healthy subjects and T2D patients over a wide range of BMI. Global DNA methylation was increased in both types of tissue in T2D patients (VAT, $p=0.1940$; , $\mathrm{p}=0.0297$; Fig. $1 \mathrm{~A}$ and $1 \mathrm{~F}$, respectively). The increase in VAT was not statistically significant. However, when categorizing enrolled subjects according to BMI (lean $<25 \mathrm{~kg} / \mathrm{m}^{2}$, or overweight and obese $\geq 25 \mathrm{~kg} / \mathrm{m}^{2}$ ), a greater difference in global DNA methylation was observed (VAT, $\mathrm{p}=0.0026$; $\mathrm{L}, \mathrm{p}=0.0001$; Fig. $1 \mathrm{~B}$ and $1 \mathrm{G}$, respectively), with higher global DNA methylation in overweight and obese subjects. What is more, a strong positive correlation was observed between global DNA methylation values measured in both types of tissue and BMI (VAT, $\mathrm{R}=0.53, \mathrm{p}=0.0143$; $\mathrm{L}$, $\mathrm{R}=0.54, \mathrm{p}=0.0122$; Fig. $1 \mathrm{C}$ and $1 \mathrm{H}$, respectively). These results suggest the strong influence of BMI on global DNA methylation.

Next, we were interested if global DNA methylation is changed between insulin-resistant vs insulin sensitive patients, Indeed, the global DNA methylation rate correlated positively with IR measured based on 2 IR ratios, HOMA-IR and QUICKI. A strong positive correlation was observed between global DNA methylation and HOMA-IR measured in VAT $(\mathrm{R}=0.61, \mathrm{p}=0.0048$, Fig. $1 \mathrm{D})$ and in $\mathrm{L}(\mathrm{R}=0.51, \mathrm{p}=0.0183$, Fig. $1 \mathrm{I})$. On the other hand, 
Table 2. Characterization of clinical and biochemical features enrolled between (A - visceral adipose tissue; B - lymphocytes)

A

\begin{tabular}{|c|c|c|c|c|c|c|}
\hline Biochemical feature & $\begin{array}{l}\text { Control group } \\
(\text { mean } \pm S D)\end{array}$ & $\begin{array}{c}\text { T2DM } \\
\text { (mean } \pm \mathrm{SD})\end{array}$ & $\begin{array}{l}\text { p-value } \\
\text { (t-test) }\end{array}$ & $\begin{array}{l}\text { Lean }\left(<25 \mathrm{~kg} / \mathrm{m}^{2}\right) \\
\quad(\text { mean } \pm \mathrm{SD})\end{array}$ & $\begin{array}{c}\text { Obese } \\
\left(\geq 25 \mathrm{~kg} / \mathrm{m}^{2}\right) \\
(\mathrm{mean} \pm \mathrm{SD})\end{array}$ & $\begin{array}{l}\text { p-value } \\
\text { (t-test) }\end{array}$ \\
\hline $\operatorname{Sex}[F / M]^{1}$ & $9 / 17$ & $6 / 3$ & - & $6 / 8$ & $9 / 12$ & - \\
\hline Age [years] & $47 \pm 15$ & $52 \pm 10$ & NS & $47 \pm 17$ & $51 \pm 10$ & NS \\
\hline BMI $\left[\mathrm{kg} / \mathrm{m}^{2}\right]$ & $24.4 \pm 5.1$ & $31.8 \pm 6.2$ & 0.0012 & $22.5 \pm 2.4$ & $30.2 \pm 3.4$ & $<0.0000$ \\
\hline Glucose [mg/dL] & $95 \pm 14$ & $146 \pm 33$ & $<0.0001$ & $105 \pm 31$ & $122 \pm 64$ & NS \\
\hline Insulin [uU/mL] & $7.2 \pm 8$ & $25.7 \pm 22$ & 0.0295 & $10 \pm 19$ & $42.5 \pm 27$ & 0.0368 \\
\hline $\mathrm{CHOL}[\mathrm{mg} / \mathrm{dL}]$ & $173 \pm 38$ & $169 \pm 81$ & NS & $209 \pm 22$ & $222 \pm 32$ & NS \\
\hline TG [mg/dL] & $160 \pm 48$ & $174 \pm 59$ & NS & $104 \pm 50$ & $228 \pm 103$ & 0.0126 \\
\hline LDL [mg/dL] & $120 \pm 33$ & $81 \pm 40$ & NS & $122 \pm 14$ & $146 \pm 30$ & NS \\
\hline $\mathrm{HDL}[\mathrm{mg} / \mathrm{dL}]$ & $46 \pm 11$ & $41 \pm 11$ & NS & $62.5 \pm 26$ & $43.3 \pm 12$ & 0.0382 \\
\hline HOMA-IR & $1.6 \pm 1.8$ & $8.9 \pm 11.7$ & 0.0236 & $1.03 \pm 1$ & $5.05 \pm 7$ & 0.0500 \\
\hline QIUCKI & $0.382 \pm 0.04$ & $0.318 \pm 0.03$ & 0.0019 & $0.399 \pm 0.04$ & $0.336 \pm 0.05$ & 0.0029 \\
\hline IL-6 [pg/uL] & $18.18 \pm 10.5$ & $22.23 \pm 16$ & NS & $19.9 \pm 6.7$ & $29.5 \pm 27$ & 0.0426 \\
\hline TNF-a [pg/uL] & $2.5 \pm 0.67$ & $1.7 \pm 1.15$ & NS & $2.4 \pm 0.8$ & $2.11 \pm 0.99$ & NS \\
\hline Adiponectin [pg/uL] & $16.5 \pm 7.3$ & $11.5 \pm 6.9$ & 0.0299 & $16.2 \pm 5.3$ & $10.5 \pm 3.6$ & 0.0276 \\
\hline
\end{tabular}

B

\begin{tabular}{|c|c|c|c|c|c|c|}
\hline Biochemical feature & $\begin{array}{l}\text { Control group } \\
\text { (mean } \pm \mathrm{SD})\end{array}$ & $\begin{array}{c}\text { T2DM } \\
(\text { mean } \pm \mathrm{SD})\end{array}$ & $\begin{array}{l}\text { p-value } \\
\text { (t-test) }\end{array}$ & $\begin{array}{l}\text { Lean }\left(<25 \mathrm{~kg} / \mathrm{m}^{2}\right) \\
\quad(\text { mean } \pm \mathrm{SD})\end{array}$ & $\begin{array}{c}\text { Obese } \\
\left(\geq 25 \mathrm{~kg} / \mathrm{m}^{2}\right) \\
(\mathrm{mean} \pm \mathrm{SD})\end{array}$ & $\begin{array}{l}\mathrm{p} \text {-value } \\
\text { (t-test) }\end{array}$ \\
\hline Sex [F/M] & $10 / 11$ & $5 / 8$ & - & $6 / 5$ & $11 / 12$ & - \\
\hline Age [years] & $50 \pm 7$ & $50 \pm 6$ & NS & $46 \pm 3.7$ & $51 \pm 6.8$ & NS \\
\hline BMI [kg/m²] & $27.6 \pm 3.8$ & $31.7 \pm 3.4$ & 0.0261 & $23 \pm 1.1$ & $31 \pm 3.2$ & 0.0008 \\
\hline Glucose [mg/dL] & $89 \pm 7.9$ & $182 \pm 70$ & 0.0019 & $92 \pm 6.8$ & $151 \pm 72$ & NS \\
\hline Insulin [uU/mL] & $4.0 \pm 0.8$ & $8.2 \pm 2.3$ & 0.0009 & $5.3 \pm 2.8$ & $6,22 \pm 3.15$ & NS \\
\hline $\mathrm{CHOL}[\mathrm{mg} / \mathrm{dL}]$ & $200 \pm 38$ & $190 \pm 49$ & NS & $214 \pm 62$ & $222 \pm 112$ & NS \\
\hline $\mathrm{TG}[\mathrm{mg} / \mathrm{dL}]$ & $111 \pm 45$ & $202 \pm 130$ & NS & $65 \pm 35$ & $175 \pm 112$ & NS \\
\hline LDL [mg/dL] & $143 \pm 42$ & $120 \pm 54$ & NS & $114 \pm 57$ & $135 \pm 48$ & NS \\
\hline $\mathrm{HDL}[\mathrm{mg} / \mathrm{dL}]$ & $68 \pm 18$ & $43 \pm 7$ & 0.0009 & $86 \pm 12$ & $49 \pm 13$ & 0.0003 \\
\hline HOMA-IR & $1.3 \pm 1.4$ & $3.6 \pm 1.3$ & 0.0012 & $1.9 \pm 1.99$ & $2.5 \pm 1.82$ & NS \\
\hline QIUCKI & $0.395 \pm 0.04$ & $0.318 \pm 0.01$ & $<0.0000$ & $0.372 \pm 0.04$ & $0.346 \pm 0.05$ & NS \\
\hline IL-6 [pg/uL] & $16.2 \pm 5.6$ & $22.2 \pm 3.1$ & NS & $8.0 \pm 1.6$ & $16.1 \pm 3.1$ & NS \\
\hline TNF-a [pg/uL] & $2.8 \pm 0.35$ & $3.6 \pm 0.6$ & NS & $2.7 \pm 0.3$ & $2.7 \pm 0.6$ & NS \\
\hline Adiponectin [pg/uL] & $11.4 \pm 5$ & $11.5 \pm 4.9$ & NS & $13.9 \pm 9.4$ & $12.8 \pm 3.8$ & NS \\
\hline
\end{tabular}

F - female; M - male; BMI - body mass index; CHOL - cholesterol; TG - triglicerydes; LDL - low-density lipoprotein; HDL - high-density lipoprotein; HOMA-IR - homeostatic insulin resistance; QIUCKI - quantitative insulin sensitivity check index; IL-6 - interleukin 6; TNF-a - tumor necrosis factor a; NS - statistically not important; bold text - statistically significant.

a negative correlation was observed between global DNA methylation and QUICKI measured in VAT $(\mathrm{R}=-0.41$, $\mathrm{p}=0.0475$, Fig. 1E) and in $\mathrm{L}(\mathrm{R}=-0.51, \mathrm{p}=0.0191$, Fig. $1 \mathrm{~J})$.

\section{DNA methyltransferase expression}

Faced with differentially methylated DNA within the investigated groups, the expression rate of 3 main DNA methyltransferases was analyzed in both types of tissue in order to determine which DNA methyltransferase is responsible for various profiles of global DNA methylation. In both types of tissue, DNMT3a was upregulated in obese T2D patients compared to controls, with no differences in the expression rate of the other 2 methyltransferases, $D N M T 1$ and DNMT3b. In VAT the expression rate of DMNT3a was 1.92 times higher $(\mathrm{p}=0.0204)$ in T2D patients compared to controls (Fig. 2A). In L the expression rate of DNMT3a was 1.59 times higher $(\mathrm{p}=0.0052)$ 
A
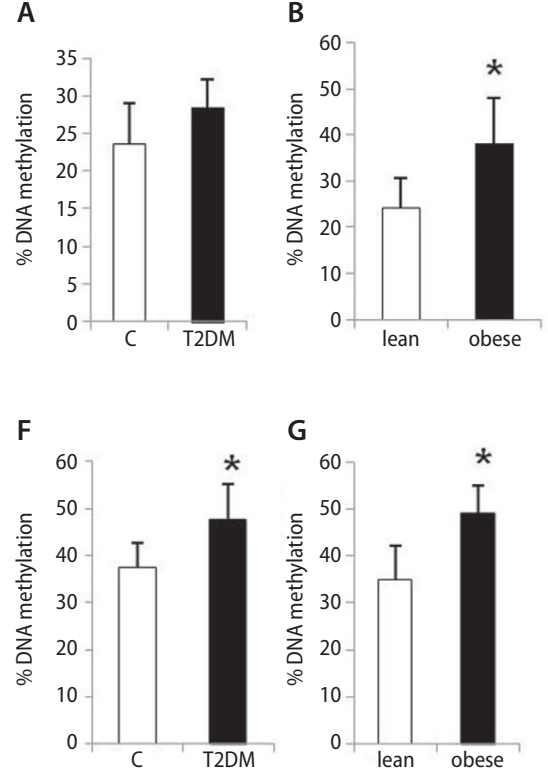

C

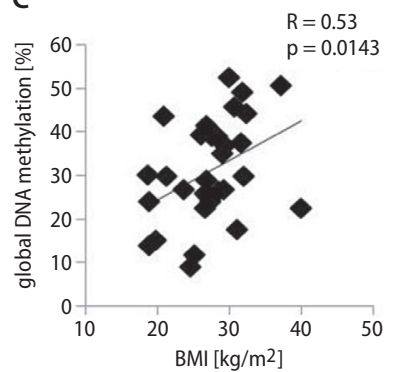

$\mathrm{H}$

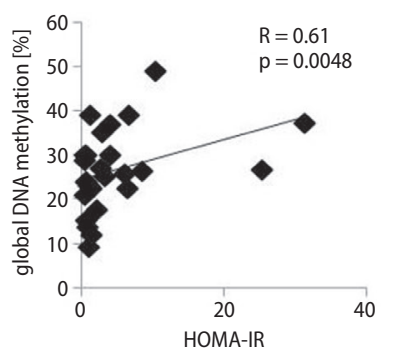

I

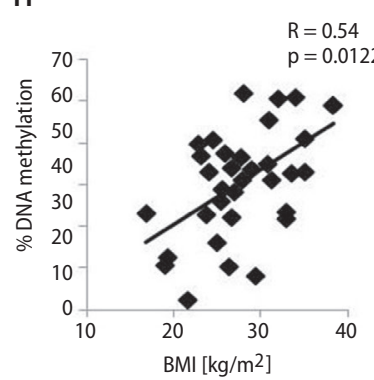

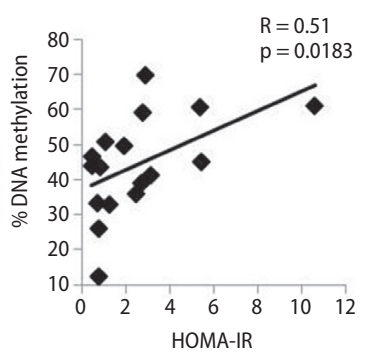

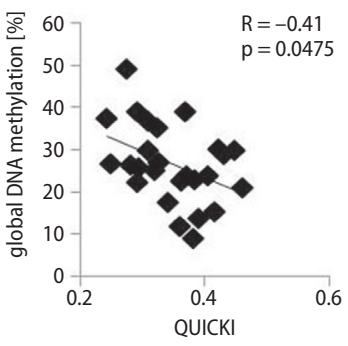

J

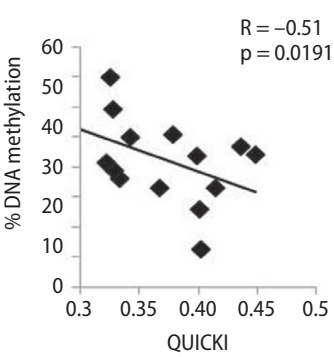

Fig. 1. Effect of global DNA methylation on insulin sensitivity

Comparison of global DNA methylation in VAT (A and B) and in L (F and G) between T2D and controls and between lean and obese patients. Correlation between global DNA methylation in VAT and BMI (C), HOMA-IR (D) and QUICKI (E); global DNA methylation in L and BMI (H), HOMA-IR (I) and QUICKI (J).
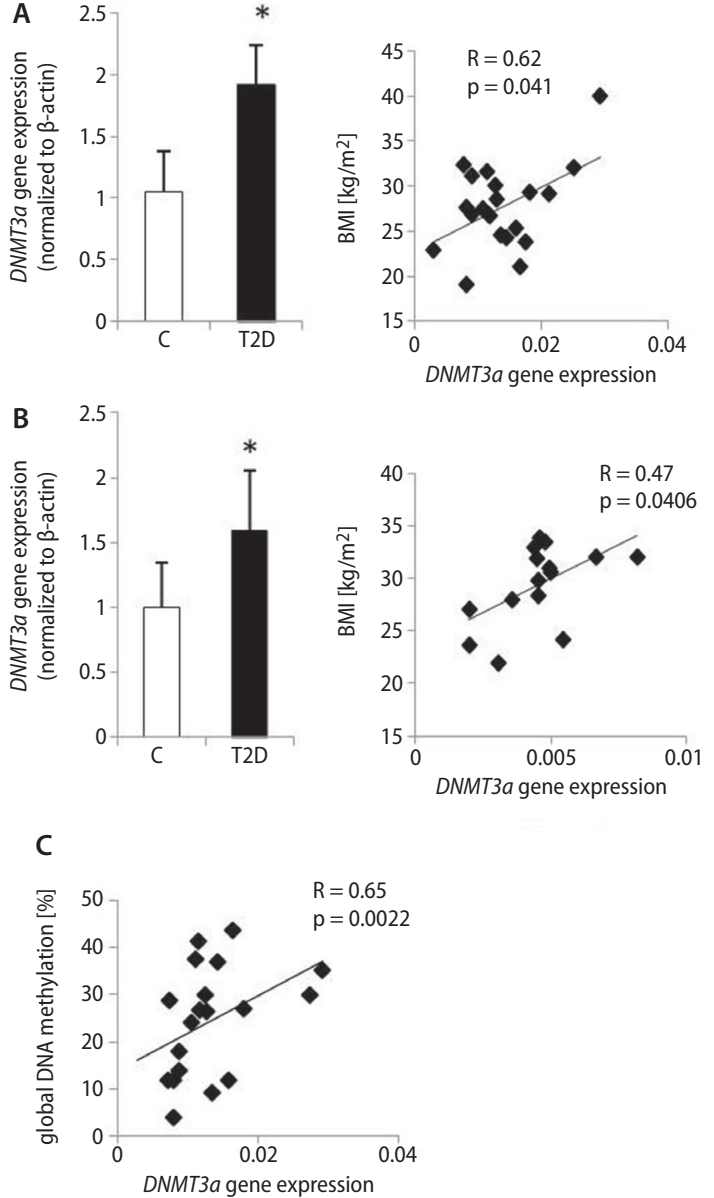

Fig. 2. The expression rate of DNMT3a methyltransferase

The expression of DNMT3a gene in VAT (A) and in $L(B)$ of enrolled patients and its correlation with BMI. Correlation between expression of DNMT3a gene and global DNA methylation observed in VAT (C). in T2D patients compared to controls (Fig. 2B), again with no changes detected in the gene expression of the other 2 DNA methyltransferases. Moreover, DNMT3a showed a positive correlation with BMI within investigated individuals in both types of tissue (VAT, $\mathrm{R}=0.62$, $\mathrm{p}=0.0041$, Fig. 2A; L, $\mathrm{R}=0.47, \mathrm{p}=0.0406$, Fig. 2B). Furthermore, the DNMT3a expression rate correlated positively with global DNA methylation in VAT $(\mathrm{R}=0.65, \mathrm{p}=0.0022$, Fig. 2C); however, a relatively weak positive correlation was observed in L.

In order to evaluate the influence of increased DNMT3a on insulin sensitivity, we investigated the correlation the mRNA level of DNMT3a measured in both VAT and $\mathrm{L}$ with IR ratios. The mRNA level of DNMT3a correlated positively with HOMA-IR (VAT, $\mathrm{R}=0.59 ; \mathrm{L}, \mathrm{R}=0.52$ ) and negatively with QUICKI (VAT, $\mathrm{R}=-0.48$; $\mathrm{L}, \mathrm{R}=-0.46$ ); however, correlations were close to being significant with the p-value slightly exceeding the limit value of 0.05 . No correlation between IR ratios and other DNMTs were observed.

These results link obesity with overexpression of $D N M T 3 a$ as a possible reason for global DNA hypermethylation in obesity and a possible reason for IR development.

\section{Insulin pathway gene expression and promoter methylation}

Global DNA methylation was shown to strongly correlate with IR in both types of tissues; accordingly, the gene expression rate and promoter methylation status of 3 main genes belonging to the insulin signaling pathway were investigated, namely the INSR (insulin receptor), 

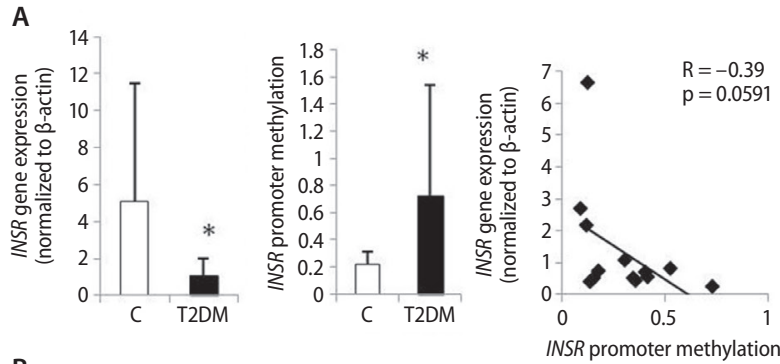

B
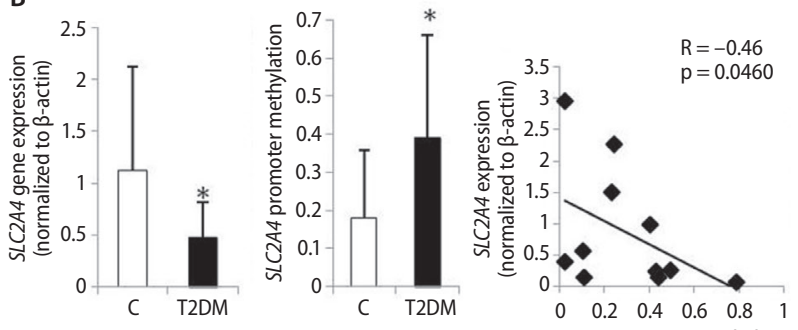

SLC2A4 promoter methylation
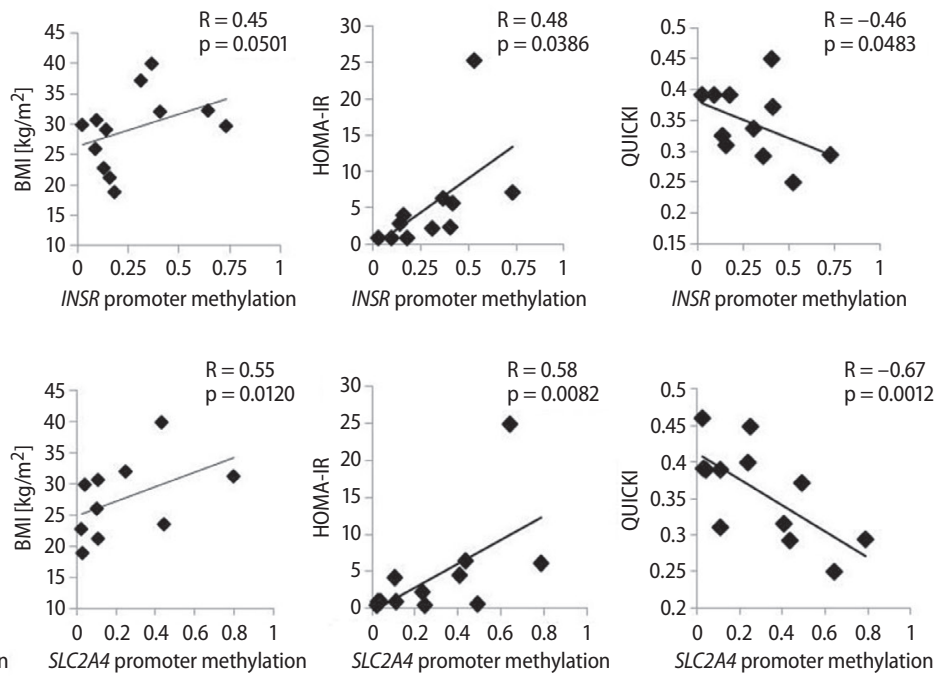

Fig. 3. Promoter methylation of insulin pathway genes

The differences in expression and methylation profile of promoters of 2 genes belonging to insulin signaling pathway: INSR gene (A) ad SLC2A4 gene (B) in VAT along with correlation of promoter methylation with gene expression, BMI and IR.

PIK3R1 (phosphoinositide-3-kinase regulatory subunit 1 ), and SLC2A4 genes (solute carrier family 2, facilitated glucose transporter, member 4). First, the gene expression rate was analyzed in both the L and VAT of the enrolled individuals. There was no difference in the expression rate of analyzed genes in $L$ between the studied groups. SLC2A4 gene expression was slightly reduced and PIK3R1 gene expression slightly increased in T2D patients, though without statistical significance. Nor were there any statistically significant differences in promoter methylation between study groups of analyzed genes in L, although the global DNA methylation rate in $\mathrm{L}$ was increased in T2D patients.

All 3 examined genes displayed a reduced expression rate in the VAT of T2D patients when compared to control subjects.

The INSR gene was downregulated in the VAT of T2D patients ( $p=0.0355$, Fig. 3A); on the other hand, the promoter methylation rate of this gene was increased $(\mathrm{p}=0.0206)$. What is more, the promoter methylation rate negatively correlated with INSR gene expression $(\mathrm{R}=-0.39, \mathrm{p}=0.0591$, Fig. 3A); however without statistical significance. An interesting positive correlation was observed between INSR promoter methylation and the BMI of the investigated subjects $(\mathrm{R}=0.45, \mathrm{p}=0.05$, Fig. 3A). Subjects with BMIs under $30 \mathrm{~kg} / \mathrm{m}^{2}$ were characterized by a relatively low INSR promoter methylation rate, as opposed to subjects with BMIs over $30 \mathrm{~kg} / \mathrm{m}^{2}$, characterized by a significantly increased INSR promoter methylation rate. Furthermore, INSR promoter methylation correlated with IR in investigated individuals. A positive correlation between the methylation of INSR promoter and HOMA-IR ( $\mathrm{R}=0.48, \mathrm{p}=0.0386$, Fig. $3 \mathrm{~A})$ and a negative correlation between the methylation of INSR promoter and QUICKI $(\mathrm{R}=-0.46, \mathrm{p}=0.0483$, Fig. 3A) were observed.

The PIK3R1 gene also showed decreased expression rate in T2D patients when compared to healthy individuals ( $\mathrm{p}=0.0199$ ), along with a slightly increased rate of PIK3R1 promoter methylation measured in this group $(\mathrm{p}=0.0581)$. However, no correlation was observed between PIK3R1 promoter methylation and gene expression, BMI or IR.

The SLC2A4 gene encoding glucose transporter type 4 (GLUT4) was downregulated ( $\mathrm{p}=0.0569$, Fig. 3B) and $S L C 2 A 4$ promoter methylation upregulated $(\mathrm{p}=0.0158)$ in the VAT of T2D patients compared to controls. Furthermore, the expression rate was negatively correlated with promoter methylation $(\mathrm{R}=-0.46, \mathrm{p}=0.0460$, Fig. $3 \mathrm{~B})$. Interestingly, the promoter methylation of the $S L C 2 A 4$ gene positively correlated with BMI within investigated individuals ( $\mathrm{R}=0.55, \mathrm{p}=0.012$, Fig. 3B). What is more, $S L C 2 A 4$ promoter methylation displayed a positive correlation with HOMA-IR $(\mathrm{R}=0.58, \mathrm{p}=0.0082$, Fig. $3 \mathrm{~B})$ and a negative correlation with QUICKI $(\mathrm{R}=-0.67, \mathrm{p}=0.0012$, Fig. 3B) in investigated subjects.

\section{Discussion}

In the present study, we investigated the influence of obesity on IR development through epigenetic mechanisms. We have shown that global DNA methylation increased in cases of obesity and correlated positively with IR. It was found that in obese individuals the expression of DNMT3a was increased, which could be the reason for the subsequent increase in global and site-specific DNA methylation, including promoters of main genes belonging to the insulin pathway (INSR, SLC2A4). 
The global DNA methylation rate is tissue-specific; therefore, 2 different types of tissue were investigated in the present study in order to better assess their association with obesity and IR. Peripheral lymphocytes have been widely studied by many researchers, with various outcomes. In some studies, there was no association between BMI and global DNA methylation ${ }^{24-26}$, while others showed results contradictory to ours, in which global DNA methylation negatively correlated with $\mathrm{BMI} .{ }^{27}$ In the present study, we showed increased global DNA methylation in the lymphocytes of obese individuals, which corresponds to other studies. ${ }^{28,29}$ What is more, global DNA methylation measured in lymphocytes showed associations with IR (assessed based on HOMA-IR and QUICKI). Similar results were obtained by others who showed a positive association between global DNA methylation and fasting glucose levels ${ }^{30,31}$ or HOMA-IR ${ }^{32}$ in those cells. Although a positive correlation between global DNA methylation and IR has been shown in the present study, no significant changes, either in gene expression or in the promoter methylation profile of insulin pathway genes, were observed. Further research needs to be done in order to draw specific conclusions, especially on a larger number of investigated subjects. It is also possible that different patterns of DNA methylation in insulin-resistant subjects influence other pathways or genes important for proper lymphocytes metabolisms, like cytokine or inflammatory markers secretion, which might as well influence insulin sensitivity. Indeed, an inverse relationship between methylation of leptin and adiponectin promoters in peripheral blood samples and IR was observed by García-Cardona et al. ${ }^{33}$ Similarly, a GWAS study performed by $\mathrm{Su}$ et al. ${ }^{34}$ also showed a correlation between the methylation status of the lymphocyte antigen 86 (LY86) gene and obesity, IR, and inflammatory markers, which provides further evidence of the influence of epigenetic regulation on IR and obesity-related disorders.

Peripheral blood lymphocytes constitute relatively good study material with respect to their easy collection and isolation methods; however, the proper cells for the evaluation of IR are adipocytes or skeletal muscles, because these tissues utilize the greatest amount of glucose provided along with food in an insulin-dependent manner. Therefore, global DNA methylation and associations with IR were investigated in VAT samples collected from patients undergoing abdominal surgery. Similarly to lymphocytes, positive associations between DNA methylation, BMI and IR were shown. We have shown that, in both types of investigated tissue, global DNA methylation differed between lean and obese subjects, despite a relatively low number of investigated subjects. Furthermore, we observed a positive association between global DNA methylation and IR among enrolled subjects. The implication of epigenetic regulation in IR pathogenesis was also confirmed when analyzing the DNMT3a expression rate within enrolled individuals. DNMT3a correlated positively with BMI and
IR ratios. The correlation with IR ratios (HOMA-IR and QUICKI) did not reach significance; however, the overall relationship was noticed. For sure, by increasing the number of investigated subjects we would obtain statistical significance.

Taking everything together, obesity influences global DNA methylation level in VAT and in lymphocytes by stimulating the expression rate of DNA methyltransferases, mainly DNMT3a. We have concluded that if there is a positive correlation between DNA methylation and IR, some insulin pathway genes must be epigenetically regulated by promoter methylation. Indeed, 2 of the 3 investigated genes were shown to be differentially methylated at the promoter sites; moreover, the methylation status correlated positively with BMI and IR ratios and negatively with gene expression. Other researchers, such as BarajasOlmos et al., ${ }^{35}$ provided further evidence that an altered DNA methylation rate of numerous genes (mainly glucose metabolism, lipid metabolism and cell-cycle regulation genes) is a mechanism that may be involved in the pathogenesis of obesity-related disorders, including T2D.

To the best of the author's knowledge, there are only a few reports concerning the epigenetic regulation of insulin pathway genes. Jones et al. ${ }^{36}$ demonstrated a decreased INSR expression rate in the subcutaneous adipose tissue of women with the influence of obesity, not of PCOS, on the expression of the INSR gene. The IRS1 and SLC2A4 genes exhibited a decreased expression rate, which correlated with an increase in promoter methylation in the skeletal muscle of adult rats which had been undernourished during the fetal stage. ${ }^{37}$ The greatest difference in gene expression and promoter methylation of both genes was seen in the $20^{\text {th }}$ week of postnatal life, which correlated with increased body weight and IR in those rats.

The relationship between DNA methylation and IR has been shown by other researchers, who described promoter methylation of other genes regulating IR, such as the adiponectin ${ }^{19}$, leptin and PPAR $\gamma$ genes, etc. ${ }^{11-13}$ The potential mechanism regulating the methylation status of the adiponectin gene was related to increased expression of DNMT1, stimulated by TNF- $\alpha .{ }^{19}$ In our study, we have shown altered expression of DNMT3a in both types of tissues, as the potential reason for differently methylated global and sitespecific DNA methylation, especially insulin signaling pathway genes. DNMT3a was previously implicated with obesity-induced IR development, as Dnmt3a knock-out mice are protected from diet-induced IR. ${ }^{38}$ Our results confirm the implication of DNMT3a with epigenetic regulation of IR in humans. There was no association between 2 other DNA methyltransferases (DNMT1 and DNMT3b) and insulin resistance; therefore, $D N M T 3 a$ was selectively shown to play a key role in obesity-related IR pathogenesis.

Summarizing all of the data described above (ours and others ${ }^{19,11-13,33-35}$ ), we suggest that IR is epigenetically regulated and thus potentially could be reversed. However, this statement has not been confirmed to date. 


\section{ORCID iDs}

Małgorzata Małodobra-Mazur (1) https://orcid.org/0000-0002-9864-5928 Aneta Alama (1) https://orcid.org/0000-0001-8428-1089 Dorota Bednarska-Chabowska (1) https://orcid.org/0000-0002-8920-7571 Dorota Pawelka (1) https://orcid.org/0000-0003-2077-7629 Aneta Myszczyszyn (1) https://orcid.org/0000-0003-3138-7554 Tadeusz Dobosz (1) https://orcid.org/0000-0003-0413-9109

\section{References}

1. Nguyen DM, El-Serag HB. The epidemiology of obesity. Gastroenterol Clin North Am. 2010;39(1):1-7.

2. Brady MJ, Saltiel AR. Closing in on the cause of insulin resistance and type 2 diabetes. J Clin Invest 1999;104(6):675-676.

3. Drong AW, Lindgren $\mathrm{CM}, \mathrm{McC}$ arthy $\mathrm{MI}$. The genetic and epigenetic basis of type 2 diabetes and obesity. Clin Pharmacol Ther. 2012;92(6): 234-237.

4. Hamilton JP. Epigenetics: Principles and practice. Dig Dis. 2011;29(2): 130-135.

5. Londono Gentile T, Lu C, Lodato PM, et al. DNMT1 is regulated by ATPcitrate lyase and maintains methylation patterns during adipocyte differentiation. Mol Cell Biol. 2013;33(19):3864-3878.

6. Deaton AM, Bird A. CpG islands and the regulation of transcription. Genes Dev. 2011;25(10):1010-1022.

7. Zhang Q, Ramlee MK, Brunmeir R, Villanueva CJ, Halperin D, Xu F. Dynamic and distinct histone modifications modulate the expression of key adipogenesis regulatory genes. Cell Cycle. 2012;11(23):4310-4322.

8. Anamika K, Krebs AR, Thompson J, Poch O, Devys D, Tora L. Lessons from genome-wide studies: An integrated definition of the coactivator function of histone acetyl transferases. Epigenetics Chromatin. 2010;3(1):18-28.

9. Riccio A. New endogenous regulators of class I histone deacetylases. Sci Signal. 2010;3(103):pe1. doi:10.1126/scisignal.3103pe1

10. Gregoretti IV, Lee YM, Goodson HV. Molecular evolution of the histone deacetylase family: Functional implications of phylogenetic analysis. J Mol Biol. 2004;338(1):17-31.

11. Pietiläinen $\mathrm{KH}$, Ismail $\mathrm{K}$, Järvinen $\mathrm{E}$, et al. DNA methylation and gene expression patterns in adipose tissue differ significantly within young adult monozygotic BMI-discordant twin pairs. Int J Obes (Lond). 2016:40(4):654-661.

12. Arner P, Sinha I, Thorell A, Rydén M, Dahlman-Wright K, Dahlman I. The epigenetic signature of subcutaneous fat cells is linked to altered expression of genes implicated in lipid metabolism in obese women. Clin Epigenetics. 2015;7:93.

13. Drogan D, Boeing H, Janke J, et al. Regional distribution of body fat in relation to DNA methylation within the LPL, ADIPOQ and PPARY promoters in subcutaneous adipose tissue. Nutr Diabetes. 2015;5(7):e168

14. Zheng $L D$, Linarelli $L E$, Liu $L$, et al. Insulin resistance is associated with epigenetic and genetic regulation of mitochondrial DNA in obese humans. Clin Epigenetics. 2015;7:60.

15. Benton MC, Johnstone A, Eccles D, et al. An analysis of DNA methylation in human adipose tissue reveals differential modification of obesity genes before and after gastric bypass and weight loss. Genome Biol. 2015;16:8.

16. Crujeiras AB, Diaz-Lagares A, Moreno-Navarrete JM, et al. Genomewide DNA methylation pattern in visceral adipose tissue differentiates insulin-resistant from insulin-sensitive obese subjects. Transl Res. 2016;178:13-24.e5.

17. Vaquero A, Reinberg D. Calorie restriction and the exercise of chromatin. Genes Dev. 2009;23(16):1849-1869.

18. Wheatley KE, Nogueira LM, Perkins SN, Hursting SD. Differential effects of calorie restriction and exercise on the adipose transcriptome in diet-induced obese mice. J Obes. 2011;2011:265417.
19. Kim AY, Park YJ, Pan X, et al. Obesity-induced DNA hypermethylation of the adiponectin gene mediates insulin resistance. Nat Commun. 2015;3:585.

20. Malodobra M, Pilecka A, Gworys B, Adamiec R. Single nucleotide polymorphisms within functional regions of genes implicated in insulin action and association with the insulin resistant phenotype. Mol Cell Biochem. 2011;349(1-2):187-193.

21. Kelley DE, Thaete FL, Troost F, Huwe T, Goodpaster BH. Subdivision of subcutaneous abdominal adipose tissue and insulin resistance. Am J Physiol Endocrinol Metab. 2000;278(5):941-948.

22. Ruano M, Silvestre V, Castro R, et al. HOMA, QUICKI and MFfm to measure insulin resistance in morbid obesity. Obes Surg. 2006;16(5):549-553.

23. Pfaffl MW. A new mathematical model for relative quantification in real-time RT-PCR. Nucleic Acids Res. 2001;29(9):2002-2007.

24. Zhang FF, Cardarelli R, Carroll J, et al. Significant differences in global genomic DNA methylation by gender and race/ethnicity in peripheral blood. Epigenetics. 2011;6(5):623-629.

25. Gomes MVM, Toffoli LV, Arruda DW, et al. Age-related changes in the global DNA methylation profile of leucocytes are linked to nutrition but are not associated with the MTHRF C677T genotype or to functional capacities. PLoS One. 2012;7(12):52570.

26. Ulrich CM, Toriola AT, Koepl LM, et al. Metabolic, hormonal and immunological association with global DNA methylation among postmenopausal women. Epigenetics. 2012;7(9):1020-1028.

27. Zhang $F$, Santell $R$, Wolff $M$. White blood cell global methylation and IL-6 promoter methylation in association with diet and lifestyle risk factors in a cancer-free population. Epigenetics. 2012;7(6):606-614.

28. Kim M, Long TI, Arakawa K, Wang R, Yu MC, Laird PW. DNA methylation as a biomarker for cardiovascular disease risk. PLoS One. 2010; 5(3):9692.

29. Cash HL, McGarvey ST, Houseman EA, et al. Cardiovascular disease risk factors and DNA methylation at the LINE-1 repeat region in peripheral blood from Samoan Islanders. Epigenetics. 2011;6(10):1257-1264.

30. Oggiioni C, Lara J, Wells JCK, Soroka K, Siervo M. Shifts in population dietary patterns and physical inactivity as determinants of global trends in the prevalence of diabetes: An ecological analysis. Nutr Metab Cardiovasc Des. 2014;24(10):1105-1111.

31. Uusitupa M. Gene-diet interaction in relation to the prevention of obesity and type 2 diabetes: Evidence from the Finnish Diabetes Prevention Study. Nutr Metab Cardiovasc Dis. 2005;15(3):225-233.

32. Bernstein BE, Stamatoyannopoulos JA, Costello JF, et al. The NIH roadmap epigenomics mapping consortium. Nat Biotechnol. 2010; 28(10):1045-1048.

33. García-Cardona MC, Huang F, García-Vivas JM, et al. DNA methylation of leptin and adiponectin promoters in children is reduced by the combined presence of obesity and insulin resistance. Int J Obes (Lond). 2014;38(11):1457-1465.

34. Su S, Zhu H, Xu X, et al. DNA methylation of the LY86 gene is associated with obesity, insulin resistance, and inflammation. Twin Res Hum Genet. 2014;17(3):183-191.

35. Barajas-Olmos F, Centeno-Cruz F, Zerrweck C, et al. Altered DNA methylation in liver and adipose tissues derived from individuals with obesity and type 2 diabetes. BMC Med Genet. 2018;19(1):28.

36. Jones MR, Brower MA, Xu N, et al. Systems genetics reveals the functional context of PCOS loci and identifies genetic and molecular mechanisms of disease heterogeneity. PLoS Genet. 2015;11(8):e1005455.

37. Liu HW, Mahmood S, Srinivasan M. Developmental programming in skeletal muscle in response to overnourishment in the immediate postnatal life in rats. J Nutr Biochem. 2013;24(11):1859-1869.

38. You D, Nilsson E, Tenen DE, et al. Dnmt3a is an epigenetic mediator of adipose insulin resistance. Elife. 2017;6:e30766. 